\title{
The Application of Acoustic Emission Technique to Monitor the Early Setting Process of Cement Pastes
}

\author{
Michaela Hoduláková ${ }^{1, a}$, Libor Topolár ${ }^{1}$ and Barbara Kucharczyková ${ }^{1}$ \\ ${ }^{1}$ Brno University of Technology, Faculty of Civil Engineering, Veveři 331/95, 60200 Brno, Czech Republic
}

\begin{abstract}
The obtained physico-mechanical properties (mainly flexural and compressive strength) of cement-based composite materials depend on various factors (type of mixture, its composition, standard hardening process, proper testing, handling during transportation, etc.). Important properties to be tested include in particular properties of materials in the fresh, still plastic, state, since accurate identification of defects in building materials/structures at the early stage will allow early elimination and minimization of their future consequences. The aim of this paper is the application of the acoustic emission (AE) method for the detection of high-frequency elastic waves created by physical and chemical processes accompanying setting and hardening of cement pastes. The experiment was conducted on cement pastes produced from different cements but with the same water/cement ratio. Since there are many possible sources of $\mathrm{AE}$ and the identification of the individual sources is difficult, the monitoring of the setting cement paste was conducted simultaneously with measurements of the internal temperature. The results of these experiments can be used to expand the understanding of the various processes occurring at the early stage of setting and hardening of cement-based materials.
\end{abstract}

\section{Introduction}

The acoustic emission (AE) method is a non-destructive method (NDT) widely employed to detect damage and defects in building materials or structures. The principle of the measurement is based on monitoring of released portions of accumulated elastic energy resulting from dynamic processes that may be induced by external as well as internal forces. Monitoring of structures with the $\mathrm{AE}$ method is unique, non-invasive and passive. The $\mathrm{AE}$ method is highly sensitive and the AE signals are only associated with active events in the material (e.g. formation of hydration products, changes of the crystalline phase and formation of damage) $[1,2,3,4]$.

The AE parameters are influenced by the type of load as well as by the material characteristics of the investigated element or structure. The composition of the material itself, i.e. maximum aggregate size, aggregate/binder ratio, or the porosity of the internal structure of the investigated materials, is also a significant influence. Conditions to be met for successful implementation of the AE method therefore include a thorough understanding of the physical background of the principle of the $\mathrm{AE}$ generation by ongoing processes, awareness of the limitations rooting from the random propagation and origin of $\mathrm{AE}$, and also the limitations given by the specific technical design of the measuring apparatus and the AE sensors, e.g. their correct calibration $[5,6,7,8]$.
There are currently several standard procedures for processing and assessment of $\mathrm{AE}$ signals. One of them deals with monitoring of counts exceeding a set threshold and tracking the number of these counts in time. It may sometimes be more beneficial to use cumulative curves to display the counts over time. A larger number of counts indicates a greater number of active processes occurring within the material $[9,10]$.

The application of the $\mathrm{AE}$ method is possible for the determination of the change in plasticity, for the detection of the formation of a plastic zone before fracture, formation of fatigue, corrosion, creep, impact fracture, as well as for the determination of formation and expansion of cracks, monitoring of the formation of microstructure at the early stage of setting and hardening of the material [11].

\section{Experiment part}

Use Two cement pastes with the water/cement ratio of 0.33 (Figure 1) were produced for the purpose of the experiment. Cement paste A was manufactured with CEM I 52.5 R Portland cement and cement paste B with CEM I 42.5 R Portland cement from the cement plant Mokrá (HeidelbergCement Czech Republic). In addition to the strength class, the two cements also significantly differed in grinding fineness, where the specific surface area of CEM I $52.5 \mathrm{R}$ cement is $521 \mathrm{~m}^{2} \cdot \mathrm{kg}^{-1}$ and of CEM I $42.5 \mathrm{R} 381 \mathrm{~m}^{2} \cdot \mathrm{kg}^{-1}$.

\footnotetext{
${ }^{\text {a }}$ Corresponding author: author@e-mail.org
} 
Immediately after mixing, the pastes were poured into Vicat rings. A piezoelectric AE sensor with an integrated waveguide coated with beeswax was inserted into each ring filled with the paste. Beeswax was used to protect the waveguide against damage. After filling both rings, oil was poured in to form autogenic conditions for the ageing process of the two pastes. The measuring set-up was stored in an air-conditioned room with the temperature of $(22 \pm 1){ }^{\circ} \mathrm{C}$ and relative humidity of $(55 \pm 10) \%$. The acoustic emission signals were recorded by the equipment DAKEL XEDO [12]. The elimination of noise and other interferences was done by a suitably set threshold $(400 \mathrm{mV})$, which corresponds to the sound level above the noise level [13].

Since most of the processes occurring during setting of cement-based composites are associated with heat release, supplementary measurements of the internal temperature were employed simultaneously with the monitoring of the early stage of setting and hardening of the cement paste. The internal temperature was measured using an embedded temperature sensor connected to a MS6D data logger from the company Comet System, s.r.o.

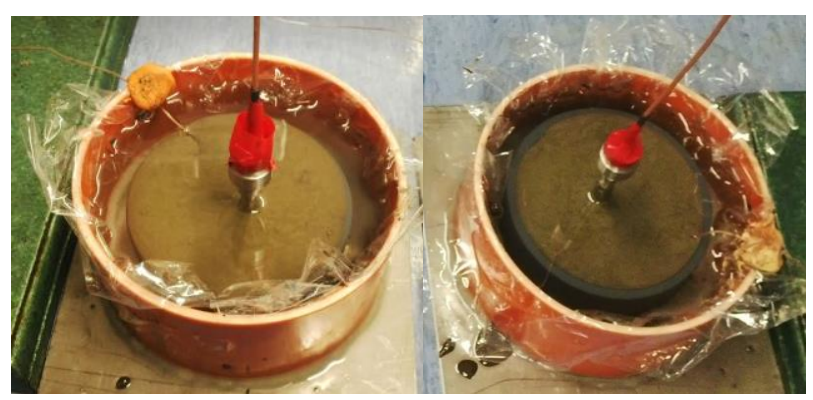

Figure 1. Paste A (left) and paste B (right).

\section{Evaluation}

The graphs (Figure 2) show the number of acoustic emission counts (NAE) and the temperature curve ( $\Delta \mathrm{T}$ is the difference between the internal temperature in the sample and the ambient temperature in the laboratory) recorded for the cement pastes ageing under autogenous conditions. The measurement results show that the greatest AE activity was detected before the increase of the internal temperature in the test specimen (during the so-called dormant period). At this stage, the positions of cement particles and of water stabilize and the plasticity of the material decreases, which demonstrates itself in a gradual loss of paste workability. From the point of view of hydration, etrignite (AFt) forms at this stage and silicates begin to dissolve leading to the formation of crystal nuclei of $\mathrm{CH}$ and $\mathrm{C}-\mathrm{S}-\mathrm{H}$. As a result, the viscosity of the cement paste begins to increase. At the end of this stage, the setting of the cement paste begins $[14,15]$.

The next stage of hydration takes place between 12 and 24 hours after mixing cement with water. At this stage, hydration of $\mathrm{C}_{3} \mathrm{~S}$ takes place and later of $\mathrm{C}_{4} \mathrm{AF}$, which leads to the formation of the foundation of the cement stone microstructure. The result of hydration at this stage is in particular the long-fibre C-S-H gel, whose fibrous structure connects the individual cement grains and is also responsible for a significant increases of the specific surface area. The formation of etrignite (AFt) continues during this stage. Due to hydration, especially of $\mathrm{C}_{3} \mathrm{~S}$, this stage is characterized by the most noticeable development of hydration heat. At this stage of hydration, the pastes exhibited the lowest AE activity. Conventional cements reach the peak of this hydration stage in 5-10 hours after mixing with water. In our case, cement paste A reached the temperature peak at 6 hours and paste B at 9 hours after mixing the cement with water $[14,15]$.

At the end of this stage, a slight increase of the development of hydration heat is usually observed, which is caused by the hydration of $\mathrm{C}_{3} \mathrm{~A}$. This process was observed only in the case of paste B (Figure 2), when the temperature decrease after reaching the maximum temperature was not as steep as in the case of paste A. Two to three days from the beginning of the hydration process, the development of hydration heat is almost beyond measurement capabilities [14, 15]. For this reason, the measurement was terminated 72 hours after mixing.
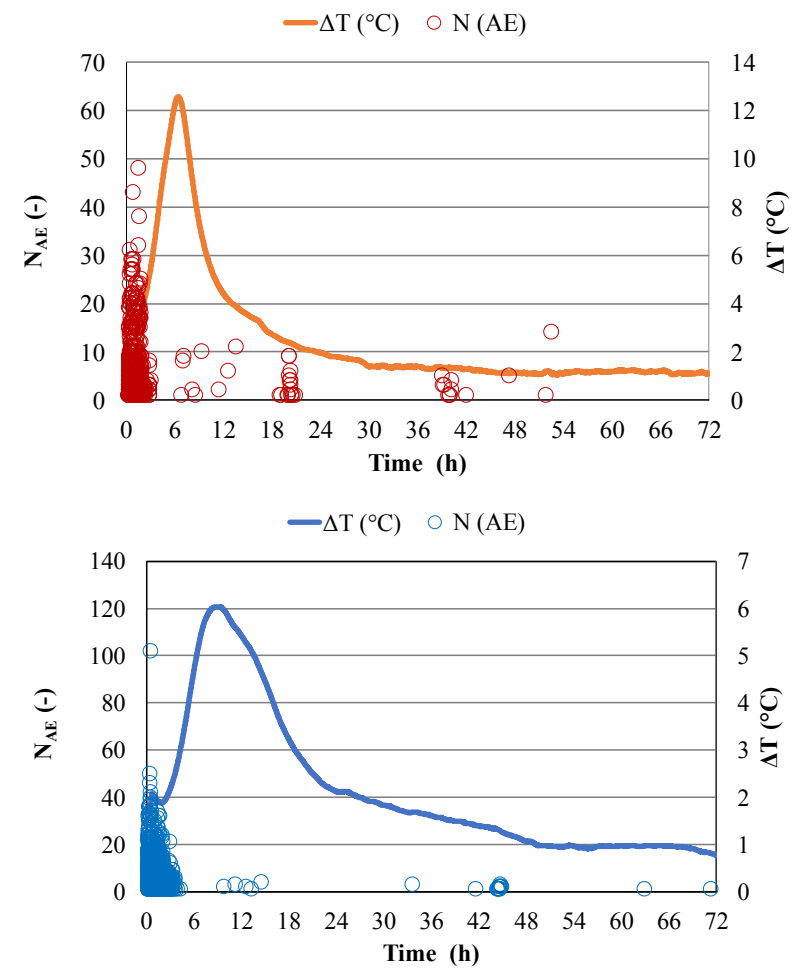

Figure 2. Cement paste A (top) and cement paste B (bottom).

The following graph (Figure 3) shows a comparison of the cement pastes based on temperature curves and a cumulative number of counts recorded from the start of the measurement. Paste B exhibited a later increase of the hydration temperature than in the case of paste $\mathrm{A}$, and its maximum reached temperature (compared to cement paste A) was lower by more than a half. The beginning of setting of cement paste B therefore occurs later. The cumulative number of $\mathrm{AE}$ counts of paste $\mathrm{B}$ reaches its peak later than in the case of paste A. The graph also shows a lower number of counts in the case of cement paste $A$ in the phase before the increase of the temperature curve, which is probably due to the fineness of cement grinding - finely ground particles with a larger 
specific surface area consume a larger amount of water for the initial wetting of the grains and also react with water more quickly, which leads to an earlier loss of workability of the produced paste (the particle settling process in the paste is faster and is accompanied by lower AE activity).

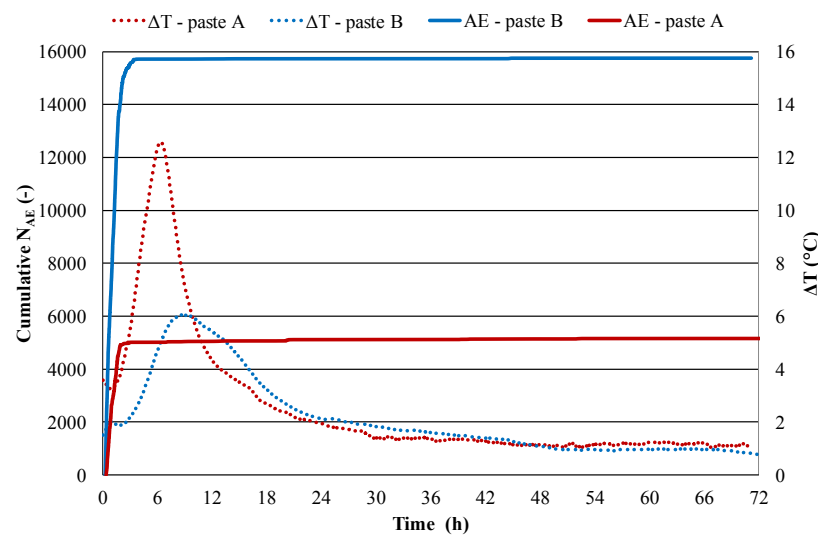

Figure 3. Comparison of cement paste A with cement paste B $(0-72$ hours).

However, more counts occur in paste $\mathrm{A}$ in the time interval just after reaching the maximum temperature. To illustrate this statement better, all counts within the first 6 hours are neglected and their cumulative number is only shown again after that time period (see Figure 4).

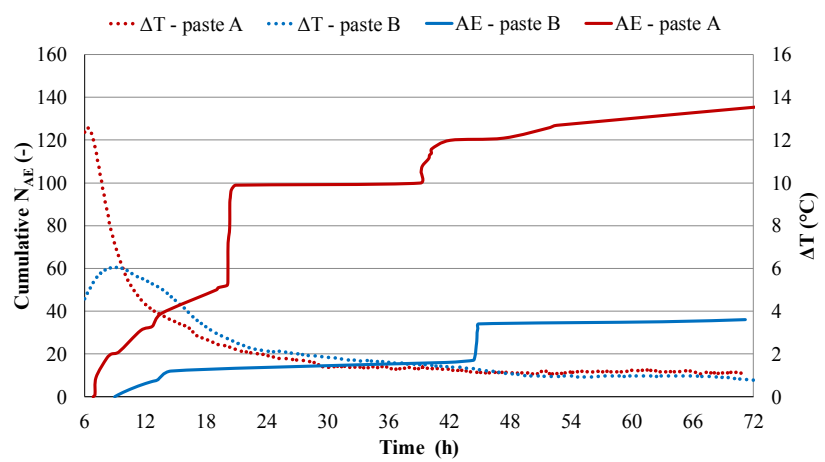

Figure 4. Comparison of cement paste A with cement paste B (6- 72 hours).

After this adjustment, it can be stated that more counts (and therefore a higher AE activity) are recorded in paste $\mathrm{A}$ than in paste $\mathrm{B}$ once the maximum temperature was reached. Scientific papers [16] include descriptions of concrete hydration processes in combination with temperature measurement, AE, linear and non-linear ultrasound spectroscopy, and it was proven that most of the activity was recorded after the temperature peak. In addition, it was found that the measured setting pastes reaching higher internal temperatures due to a more intensive hydration reaction also exhibited higher $\mathrm{AE}$ activity [16], which correlates with our results presented in Figure 4.

\section{Conclusion}

The paper presents the results of an experiment dealing with the use of the AE method for monitoring of the early stage of setting and hardening of cement pastes ageing under autogenous conditions. The results clearly demonstrate that when using the selected setting of the measuring apparatus, both monitored pastes under the given ageing conditions exhibit the highest acoustic activity in the plastic and semi-plastic phase of the solidifying process, in the so-called dormant period. From the AE perspective, the most significant changes in the internal structure occur under the given hardening conditions. During the following phase of the ageing process, which is accompanied by a gradual increase in temperature, the acoustic activity is most influenced by the absolute value of the internal temperature, where more acoustic signals were recorded for cement paste A (with higher hydration heat) than for cement paste B. In the case of both pastes, good correlation was found between the curves of cumulative $\mathrm{AE}$ count and the curves of the development of internal temperature - there is a sharp decrease of $\mathrm{AE}$ count at the moment of the temperature rise (see Figure 3). It can therefore be assumed that the AE method could serve as an alternative method for the determination of the setting times since the beginning of setting in particular is clearly visible on the cumulative AE count curve. In addition, it could also help to clarify the phenomena and processes occurring in cement-based composites ageing under autogenous conditions.

The main advantage of the AE method is that it allows monitoring of fresh cement-based composites immediately after demoulding. The $\mathrm{AE}$ is a nondestructive passive method, which does not affect the measured object and provides integral information about the current dynamic state of the material, which is its undeniable advantage. On the other hand, it also has some disadvantages. The main disadvantage is the fact that the generation of acoustic-emission "clusters" has not yet been explained and therefore makes it impossible to unambiguously interpret the measurements. Another disadvantage is the too low energy of many acoustic impulses, which causes the impulses to disappear in the noise background of the detector or are attenuated in the setting material.

\section{Acknowledgement}

This outcome has been achieved with the financial support of the Czech Science Foundation under project no. 17-14302S "Experimental analysis of the early-age volume changes in cement-based composites".

\section{References}

1. E.D. Dzaye, G. De Schutter, D. Aggelis, Study on mechanical acoustic emission sources in fresh concrete, Archives of Civil and Mechanical Engineering 18.3: 742-754. (2018) 
2. Diagnostická metoda akustické emise a její perspektivy (in Czech). Techmagazín.cz [online]. Praha: TECH MEDIA PUBLISHING [cit. 2017-0921]. Information on: http://www.techmagazin.cz/85, (2017)

3. P.R. Prem, A.R. Murthy, Acoustic emission monitoring of reinforced concrete beams subjected to four-point-bending, Applied Acoustics, 117, 28-38., (2017)

4. B. Goszczyń ska, G. Świt, W. Trąmpczyń ski, A. Krampikowska, J. Tworzewska, P. Tworzewski, Experimental validation of concrete crack identification and location with acoustic emission method, Archives of Civil and Mechanical Engineering, 12(1), 23-28. (2012)

5. J. Keprt, P. Beneš, Stanovení nejistot primární kalibrace snímačů akustické emise (in Czech), In: KOŘENSKÁ, Marta a Pavel MAZAL. Defektoskopie 2007 - 37. mezinárodní konference a výstava: Sborník př́sp ě vků proceeding. Praha: Česká společnost pro nedestruktivní testování, s. 105-110. ISBN 9788021435049. (2007)

6. K. Ohno, M. Ohtsu, Crack classification in concrete based on acoustic emission, Construction and Building Materials, 24(12), 2339-2346. (2010)

7. N.M. Bunnori, R.J. Lark, K.M. Holford, The use of acoustic emission for the early detection of cracking in concrete structures, Mag Concr Res;63(9):683-8, (2011)

8. R.V. Sagar, B.R Prasad, A review of recent developments in parametric based acoustic emission techniques applied to concrete structures, Nondestruct TestEval;27(1):47-68. (2012)

9. M. Kořenská, Aplikace akustických metod ve stavebnictvi (the part of the habilitation thesis, in Czech), VUTIUM. (2006)
10. C.U. Grosse, M. Ohtsu (Eds.), Acoustic emission testing, Springer Science \& Business Media. (2008)

11. E.D. Dzaye, G. De Schutter, D. Aggelis, Early-age monitoring of fresh cementitious material by acoustic emission, In 2nd International RILEM/COST Conference on Early age Cracking and Serviceability in Cement-based Materials and Structures (EAC-02) (Vol. 1, pp. 417-422). RILEM Publications. (2017)

12. Information on http://www.dakel.cz/index.php?pg=prod/dev/xedo_e $\mathrm{n}$

13. L. Topolár, D. Kocáb, P. Misák, L. Pazdera, M. Hoduláková, B. Kucharczyková, The Analysis of Acoustic Emission Signals Generated in Cementbased Composites During the Cyclic Loading Test, In Experimental Stress Analysis 2017. Košice: Technical University of Košice, Faculty of Mechanical Engineering, p. 402-407. ISBN: 978-80553-3166- 9. (2017)

14. G.C. Bye, Portland Cement: Composition, Production and Properties, 2nd edition: 7. The hydration of Portland cement. Thomas Telford, s. 95130. DOI: 10.1680/pccpap.27664. ISBN 978-07277-2766-4. (1999)

15. H.M. Jennings, J.J. Thomas, D. Rothstein, J.J. Chen, Handbook of porous solids, kapitola 6 - Cements as porous materials, Weinheim, Wiley-VCH (2002)

16. K. Van Den Abeele, W. Desadeleer, G. De Schutter, M. Wevers, Active and passive monitoring of the early hydration process in concrete using linear and nonlinear acoustics, Cement and Concrete Research 39, 426-432, (2009) 